\title{
Comunicação
}

[Communication]

\section{Ocorrência e caracterização molecular de Cryptosporidium em cordeiros}

[Occurrence and molecular characterization of Cryptosporidium in lambs]

\author{
F.C. Féres ${ }^{1}$, A.L. Lombardi ${ }^{1}$, M.P.P. Carvalho ${ }^{2}$, L.C.N. Mendes ${ }^{3}$, J.R. Peiró ${ }^{3}$, F.A. Cadioli $^{3}$, \\ M.V. Meireles ${ }^{3}$, S.H.V. Perri ${ }^{3}$, F.L.F. Feitosa ${ }^{3 *}$. \\ ${ }^{1}$ Aluno de pós-graduação - UNESP \\ Rua Clóvis Pestana, 793 \\ 16050-680 - Araçatuba, SP \\ ${ }^{2}$ Aluna de graduação - UNESP - Araçatuba , SP \\ ${ }^{3}$ Curso de Medicina Veterinária - FO-UNESP - Araçatuba, SP
}

O protozoário Cryptosporidium, um dos principais causadores de diarreia em cordeiros (de Graaf et al.,1999), é o responsável por grande impacto econômico em virtude de sua elevada morbidade e, em alguns casos, mortalidade (Casemore et al., 1997).

Em ovinos, as maiores taxas de infecção são observadas nas primeiras semanas de vida (Martinez et al., 2001; Quilez et al., 2003) com a maior positividade aos 21 dias (Santin et al., 2007).

A caracterização das espécies e genótipos envolvidos na criptosporidiose é de extrema relevância do ponto de vista da saúde pública, levando-se em consideração o potencial zoonótico de determinadas espécies de Cryptosporidium. Nos Estados Unidos da América e na Austrália, foram identificados, em ovinos, espécies e genótipo de Cryptosporidium com elevado potencial zoonótico (Ryan et al., 2005; Santin et al., 2007).

Os objetivos deste estudo foram determinar a ocorrência de Cryptosporidium em amostras de fezes de cordeiros, classificar as espécies e genótipos desse parasito e estimar a correlação entre ocorrência e sistema de criação, consistência das fezes, idade dos animais e grau de eliminação dos oocistos.

Recebido em 19 de janeiro de 2009

Aceito em 21 de julho de 2009

*Autor para correspondência (corresponding author)

E-mail: leydsonf@fmva.unesp.br
Colheram-se 460 amostras de fezes de cordeiros na região do município de Araçatuba, SP, provenientes de 21 propriedades rurais, mantidas sob os sistemas de criação intensiva $(n=4)$, semiintensiva $(n=8)$ e extensiva $(n=9)$. A escolha dos animais incluídos na análise foi aleatória, sendo realizada de acordo com a disponibilidade no local, independentemente da raça, do sexo, da condição física e da presença de diarreia. Os períodos das coletas foram de abril a novembro de 2006 e de abril a junho de 2007. Distribuíramse os animais em quatro grupos $(\mathrm{G})$, de acordo com a faixa etária: o grupo I foi formado por cordeiros de 0 a 7 dias ( $\mathrm{n}=147)$; o grupo II, de 8 a 15 dias $(n=136)$; o grupo III, de 16 a 22 dias $(n=122)$; e o grupo IV, de 23 a 30 dias $(n=55)$ de idade.

As amostras fecais foram obtidas diretamente do reto dos animais. O armazenamento dessas amostras foi em tubos de plásticos a $4^{\circ} \mathrm{C}$ até o momento de sua análise. Para avaliar a presença e a intensidade da diarreia na criptosporidiose, em cordeiros, foi realizado o escalonamento das fezes segundo o grau de hidratação, da seguinte forma: peletizada (p), sólida (s), amolecida (a) e líquida (1) (Ortega-Mora e Wright, 1994).

As amostras fecais foram submetidas à purificação e concentração dos oocistos por meio da sedimentação com água/éter (Meloni e Thompson, 1996). Os sedimentos foram 
armazenados a $4^{\circ} \mathrm{C}$ até o momento de sua análise microscópica, realizada por meio da técnica de coloração negativa com verde malaquita (Elliot et al., 1999). A avaliação semiquantitativa dos oocistos seguiu a seguinte nomenclatura: negativo, 0; grau 1, de 1 a 10 oocistos na lâmina; grau 2 , de 1 a 5 oocistos por campo na objetiva de 20x; grau 3, de 5 a 20 oocistos por campo na objetiva de 20x; e grau 4, acima de 21 oocistos por campo na objetiva de $20 x$.

Em todas as amostras positivas à microscopia, houve extração de DNA, segundo Meireles et al. (2007), para a posterior realização de reação em cadeia de polimerase tipo nested (nPCR) por meio da amplificação de fragmento da subunidade $18 \mathrm{~S}$ do gene RNA ribossômico, segundo Xiao et al. (2000), ou do gene da actina (Sulaiman et al., 2002). Em todas as reações, utilizaram-se água ultrapura como controle negativo, e Cryptosporidium genótipo de avestruzes, previamente identificado, como controle positivo.

Foi escolhida, aleatoriamente, uma amostra de cada propriedade em que houve animais positivos para a realização das reações de sequenciamento. Essas foram realizadas em duplicata e nas duas direções, com o DYEnamic ${ }^{\circledR}$ ET dye terminator cycle sequencing $k^{1}{ }^{1}$, utilizando-se para tanto os mesmos primers da reação de nested $\mathrm{PCR}$.

O alinhamento e a tradução das sequências de nucleotídeos foram feitos para determinação da sequência consenso, por meio do software Codoncode Aligner v. 1.5.2. ${ }^{2}$, e alinhados com o auxílio dos programas Clustal W (Thompson et al., 1997) e BioEdit Sequence Alignment Editor (Hall, 1999), tomando-se como base sequências homólogas disponíveis no GenBank.

Para verificar as associações entre o grau de consistência das fezes e de eliminação de oocistos de Cryptosporidium nas fezes de cordeiros, realizou-se o teste Kruskal-Wallis e o teste de comparações múltiplas de Dunn. Quando essas mesmas variáveis foram analisadas para cada grupo, segundo a idade, utilizou-se o coeficiente de correlação de Spearman. O teste exato de Fisher foi empregado para verificar a correlação entre os resultados das propriedades em que houve cordeiros positivos e negativos, segundo a eliminação de Cryptosporidium nas fezes, bem como entre o sistema de criação.

A análise estatística foi efetuada, empregando-se os recursos do SAS (SAS... 1999), considerados significativos quando $\mathrm{P}<0,05$ (Zar, 1999).

Observou-se que $38,1 \%(8 / 21)$ das propriedades na região de Araçatuba possuíam animais positivos para Cryptosporidium, com ocorrência de $6,7 \%(31 / 460)$ de cordeiros que eliminavam oocistos. Não houve diferença significativa entre o sistema de criação e o número de amostras positivas para Cryptosporidium.

Provavelmente, em virtude do reduzido número de animais positivos neste estudo, não foi possível verificar correlação estatística entre 0 grau de consistência das fezes, a idade e a taxa de eliminação de oocistos (Tab.1).

Dois animais com diarreia e positivos para Cryptosporidium encontravam-se no grupo de idade de 0-7 dias e com grau de eliminação de oocisto 2 e 3 . Esse resultado confirma outros já encontrados por Causapé et al. (2002), que observaram 93,3\% de cordeiros infectados por Cryptosporidium spp., na primeira semana de vida, com diarreia. No Brasil, não há relato das espécies e genótipos envolvidos nesta parasitose ovina.

Neste estudo, foram identificadas uma amostra de genótipo cervídeo, uma amostra de $C$. parvum $18 \mathrm{~S}$ rRNA tipo A, o mais comum em infecções em ruminantes, e uma amostra de $C$. parvum $18 \mathrm{~S}$ rRNA tipo B (le Blancq et al., 1997), todas com potencial zoonótico. O gene da actina foi utilizado neste estudo com o intuito de melhorar a qualidade e/ou a positividade dos animais por meio da nPCR, pois, em algumas amostras, mesmo que o animal fosse sabidamente positivo pela microscopia, tal resultado não foi confirmado ao amplificar os fragmentos da subunidade $18 \mathrm{~S}$ do gene do RNA ribossômico.

${ }^{1}$ MegaBACE GE Health Sciences, Champain, Illinois, USA. ${ }^{2}$ CodonCode Corp. Dedham, MA, USA GE Health Sciences, Champain, Illinois, USA. 
Tabela 1. Distribuição dos ovinos pelos grupos de idade de acordo com o grau de eliminação de oocistos de Cryptosporidium e de consistência das fezes com coeficiente de correlação de Spearman $\left(\mathrm{r}_{\mathrm{S}}\right)$ para cada grupo

\begin{tabular}{|c|c|c|c|c|c|c|c|c|c|c|c|c|}
\hline \multirow{3}{*}{ Grupo } & \multirow{3}{*}{$\begin{array}{c}\text { Grau de } \\
\text { eliminação } \\
\text { de oocistos }\end{array}$} & \multicolumn{8}{|c|}{ Grau de consistência das fezes } & \multirow{2}{*}{\multicolumn{2}{|c|}{ Total }} & \multirow{3}{*}{$\begin{array}{c}\mathrm{r}_{\mathrm{S}} \\
(\mathrm{P})\end{array}$} \\
\hline & & \multicolumn{2}{|c|}{ Pel } & \multicolumn{2}{|c|}{ Sol } & \multicolumn{2}{|c|}{ Amol } & \multicolumn{2}{|c|}{ Liq } & & & \\
\hline & & $\mathrm{N}$ & $\%$ & $\mathrm{~N}$ & $\%$ & $\mathrm{~N}$ & $\%$ & $\mathrm{~N}$ & $\%$ & $\mathrm{~N}$ & $\%$ & \\
\hline \multirow{5}{*}{ G I } & 0 & 56 & 38,1 & 21 & 14,3 & 61 & 41,5 & 3 & 2,0 & 141 & 95,8 & \multirow{5}{*}{$\begin{array}{c}0,116 \\
(0,1624)\end{array}$} \\
\hline & 1 & 2 & 1,4 & - & - & - & - & - & - & 2 & 1,4 & \\
\hline & 2 & - & - & - & - & 1 & 0,7 & 1 & 0,7 & 2 & 1,4 & \\
\hline & 3 & - & - & - & - & 1 & 0,7 & 1 & 0,7 & 2 & 1,4 & \\
\hline & Total & 58 & 39,5 & 21 & 14,3 & 63 & 42,8 & 5 & 3,4 & 147 & 100,0 & \\
\hline \multirow{5}{*}{ G II } & 0 & 76 & 55,9 & 26 & 19,2 & 19 & 13,9 & 4 & 2,9 & 125 & 91,9 & \multirow{5}{*}{$\begin{array}{c}0,121 \\
(0,1600)\end{array}$} \\
\hline & 2 & 3 & 2,2 & - & - & 2 & 1,5 & - & - & 5 & 3,7 & \\
\hline & 3 & 2 & 1,5 & 1 & 0,7 & 1 & 0,7 & - & - & 4 & 2,9 & \\
\hline & 4 & - & - & - & - & 2 & 1,5 & - & - & 2 & 1,5 & \\
\hline & Total & 81 & 59,6 & 27 & 19,9 & 24 & 17,6 & 4 & 2,9 & 136 & 100,0 & \\
\hline \multirow{6}{*}{ G III } & 0 & 64 & 52,5 & 22 & 18,0 & 24 & 19,7 & - & - & 110 & 90,2 & \multirow{6}{*}{$\begin{array}{c}0,044 \\
(0,6266)\end{array}$} \\
\hline & 1 & 4 & 3,3 & - & - & 3 & 2,5 & - & - & 7 & 5,7 & \\
\hline & 2 & - & - & - & - & 1 & 0,8 & - & - & 1 & 0,8 & \\
\hline & 3 & 1 & 0,8 & - & - & 1 & 0,8 & - & - & 2 & 1,6 & \\
\hline & 4 & 2 & 1,6 & - & - & 0 & 0,0 & - & - & 2 & 1,6 & \\
\hline & Total & 71 & 58,2 & 22 & 18,0 & 29 & 23,8 & - & - & 122 & 100,0 & \\
\hline \multirow{4}{*}{ G IV } & 0 & 40 & 72,7 & 11 & 20,0 & 1 & 1,8 & 1 & 1,8 & 53 & 96,4 & \multirow{4}{*}{$\begin{array}{c}-0,108 \\
(0,4345)\end{array}$} \\
\hline & 2 & 1 & 1,8 & - & & - & - & - & - & 1 & 1,8 & \\
\hline & 3 & 1 & 1,8 & - & & - & - & - & - & 1 & 1,8 & \\
\hline & Total & 42 & 76,4 & 11 & 20,0 & 1 & 1,8 & 1 & 1,8 & 55 & 100,0 & \\
\hline
\end{tabular}

$\overline{\mathrm{G} \mathrm{I}, 0} \mathbf{0} 7$ dias de idade; GII, 8 a 15 dias de idade; GIII, $\overline{16}$ a 22 dias de idade; GIV, 23 a 30 dias de idade. Pel: fezes peletizadas; Sol: fezes sólida; Amol: fezes amolecidas; Liq: fezes líquidas.

Negativo, 0; grau 1, de 1 a 10 oocistos na lâmina; grau 2, de 1 a 5 oocistos por campo na objetiva de 20x; grau 3, de 5 a 20 oocistos por campo na objetiva de 20x; grau 4, acima de 21 oocistos por campo na objetiva de 20x.

(P): probabilidade.

Embora o número de cordeiros positivos para Cryptosporidium não seja elevado na região de Araçatuba, medidas higiênicas e sanitárias devem ser tomadas a fim de se evitar a contaminação humana por esse agente, levando- se em consideração o potencial zoonótico das amostras sequenciadas.

Palavras-chave: cordeiro, Cryptosporidum, caracterização molecular

\section{ABSTRACT}

The occurrence of Cryptosporidium in fecal samples of lambs was determined in order to test correlations among the type of animal raising, feces consistence, index of oocysts elimination, animal age, and molecular characterization of species and genotypes involved in this parasitism. A total of 460 fecal samples were collected from lambs during the first 30 days of life, in various screeds of 21 farms. All samples were analyzed using malachite green negative coloration stain under microscopy. For molecular characterization of Cryptosporidium, on positive samples under microscopy, a nested PCR protocol was used for amplification of fragmentts from $18 S$ rRNA gene or actin gene. It was found 6.7\% of animals expeling oocysts of Cryptosporidium in feces of eight farms, without statistics relation among the analyzed indexes. The species and genotype involved were C. parvum type A $18 S$ rRNA, C. parvum type B $18 S$ rRNA and cervid genotype, which present a zoonotic potential of disease.

Keywords: lamb, Cryptosporidium, molecular characterization 


\section{AGRADECIMENTO}

Os autores agradecem à FAPESP pelo suporte financeiro (Processo 05/58614-8) para a realização deste trabalho. M.P.P. Carvalho é bolsista de iniciação científica da FAPESP.

\section{REFERÊNCIAS BIBLIOGRÁFICAS}

CASEMORE, D.P.; WRIGHT, S.E.; COOP, R.L. Cryptosporidium- human and animal epidemiology. In: FAYER, R. (Ed.). Cryptosporidium e Cryptosporidiose. Boca Raton: CRC, 1997. p.400-415.

CAUSAPÉ, A.C.; QUILEZ, J.; SANCHEZ, C. et al. Prevalence and analysis of potencial risk factors for Cryptosporidium parvum infection in lambs in Zaragoza (northeastern Spain). Vet. Parasitol., v.104, p. 287-298, 2002.

DE GRAAF, D.C.; VANOPDENBOSCH, E.; ORTEGA-MORA, L.M. A review of importance of cryptosporidiosis in farm animals. Int. J. Parasitol., v.29, p.1269-1287, 1999.

ELLIOT, A.; MORGAN, U.M.; THOMPSOM, R.C.A. Improved staining method for detecting Cryptosporidium oocysts in stools using malachite green. J. Gen. Appl. Microbiol., v.45, p.139-142, 1999.

HALL, T.A. BioEdit: a user-friendly biological sequence aligment editor and analysis program for Windows 95/98/NT. Nucleic Acid Symp., v.41, p.9598, 1999.

LE BLANCQ, S.; KHRAMTSOV, N.V.; ZAMANI, F. et al. Ribosomal RNA gene organization in Cryptosporidium parvum. Mol. Biochem. Parasitol., v.90, p.463-478, 1997.

MARTINEZ, R.D.R.; PRIETO, R.H.P.; VERA, E. La cryptosporidiosis en los terneiros recien nacidos. Su etiologia, patogenia, sintomas, tratamiento y profilaia. Rev. Cienc. Tecnol., v.1, p.99-108, 2001.

MEIRELES, M.V.; SOARES, R.M.; BONELLO, F. et al. Natural infection with zoonotic subtype of Cryptosporidium parvum in Capybara (Hydrochoerus hydrochaeris) from Brazil. Vet. Parasitol., v.147, p.166-170, 2007.
MELONI, B.P.; THOMPSON, R.C.A. Simplified methods for obtaining purified oocysts from mice and for growing Cryptosporidium parvum in vitro. $J$. Parasitol., v.82, p.757-762, 1996.

ORTEGA-MORA, L.M.; WRIGHT, S.E. Age-related resistance in ovine cryptosporidiosis: patterns of infection and humoral immune response. Infect. Immun., v.62, p.5003-5009, 1994

QUILEZ, J.; ACEDO, C.S.; CACHO, E. Criptosporidioses de los pequenos ruminantes. Peq. Rum., v.4, p.1-20, 2003.

RYAN, U.M.; BATH, C.; ROBERTSON, I. et al. Sheep may not be an important zoonotic reservoir for Cryptosporidium and Giardia parasites. Appl. Environ. Microbiol., v.71, p.4992-4997, 2005.

SANTIN, M.; TROUT, J.M.; FAYER, R. Prevalence and molecular characterization of Cryptosporidium and Giardia species and genotypes in sheep in Maryland. Vet. Parasitol., v.146, p.17-24, 2007.

SAS OnlineDoc $\AA$, Version 8. Cary, NC: SAS Institute, 1999.

SULAIMAN, L.M.; LAL, A.A.; XIAO,L. Molecular phylogeny and evolutionary relationships of Cryptosporidium parasites at the actin locus. $J$. Parasitol., v. 88, p. 388-394, 2002.

THOMPSON, J.D.; GIBSON, T.J.; PLEWNIAK, F. et al. The clustal $\mathrm{X}$ windows interface: flexible strategies for multiple sequence alignment aided by quality tools. Nucleic Acids Res., v.24, p.4876-4882, 1997.

XIAO L.; LIMOR J.R.; SULAIMAN I.M. et al. Molecular characterization of a Cryptosporidium isolate from a black bear. J. Parasitol., v.86, p.116670, 2000.

ZAR, J.H. Biostatistical analysis. 4. ed. New Jersey: Prentice-Hall, 1999. 663p. 